\title{
Analisis Efektivitas Kerja Ditinjau Dari Pengawasan dan Kompetensi Pegawai
}

\author{
Rembulan ${ }^{1}$, Tri Darmawati ${ }^{2}$, \\ ${ }^{1}$ Fakultas Ekonomi Bisnis Universitas PGRI Palembang, ulan64844@gmail.com \\ ${ }^{2}$ Fakultas Ekonomi Bisnis Universitas PGRI Palembang, tridarmawati@univpgri-palembang.ac.id
}

\begin{abstract}
ABSTRAK
Analisis ini mencari dampak efektivitas kerja ditinjau dari pengawasan dan kompetensi pegawai pada kantor Pengadilan Tata Usaha Negara Palembang. Data responden dikumpulkan melalui sebaran kuesioner menggunakan google form kepada 39 orang pegawai. Data-data diproses memakai aplikasi SPSS versi 23. Instrumen penelitian berupa kuisioner sebelum digunakan terlebih dahulu dilakukan pengujian dari sisi validitas dan reliabilitas. Data-data diproses menggunakan analisis normalitas, multikolonieritas, dan heteroskedastisitas. Selain itu juga digunakan analisis regresi, determinasi, dan nilai $t$, dan $F$. Berdasarkan hasil pengolahan data diperoleh persamaan regresi untuk variabel pengawasan dan kompetensi terhadap efektivitas kerja pegawai adalah $\mathrm{Y}=9.742+0.447 \mathrm{X} 1+0.352$ $\mathrm{X} 2$, kemudian pengujian hipotesis pertama $(\mathrm{H} 1)$ secara parsial menggunakan uji $t$ diperoleh data nilai signifikansi $0,004<0,05$. Artinya pengawasan dapat meningkatkan efektivitas kerja pegawai. Sedangkan untuk hipotesis kedua $(\mathrm{H} 2)$ pengujian hipotesis menggunakan uji t diperoleh nilai signifikasi $0,042<0,05$. Artinya kompetensi mampu menaikkan efektivitas kerja pegawai. Hasil uji hipotesis ketiga $(\mathrm{H} 3)$ dengan uji $F$ diperoleh nilai signifikasi $0,000<0,05$. Maka secara bersama-sama pengawasan dan kompetensi bisa memberikan peningkatan signifikan efektivitas kerja pegawai.
\end{abstract}

Kata Kunci : Pengawasan, Kompetensi, Efektivitas Kerja

\begin{abstract}
This analysis looks for the impact of work effectiveness in terms of supervision and competence of employees at the Palembang State Administrative Court office. Respondent data was collected through questionnaires using google form to 39 employees. The data was processed using the SPSS version 23 application. The research instrument was in the form of a questionnaire before being used, first tested in terms of validity and reliability. The data were processed using normality, multicollinearity, and heteroscedasticity analysis. In addition, regression analysis, determination, and $t$ and $F$ values are also used. Based on the results of data processing, the regression equation for the supervisory and competence variables on employee work effectiveness is $Y=9.742+0.447 X 1+$ 0.352 X2, then testing the first hypothesis (H1) Partially using the $t$ test, the data obtained a significance value of $0.004<0.05$. This means that supervision can increase the effectiveness of employees' work. Meanwhile, for the second hypothesis (H2), hypothesis testing using t-test obtained a significance value of $0.042<0.05$. This means that competence is able to increase the effectiveness of employees' work. The results of the third hypothesis test $(\mathrm{H} 3)$ with the $F$ test obtained a significance value of $0.000<0.05$. So together, supervision and competence can provide a significant increase in employee work effectiveness.
\end{abstract}

Keywords: Supervision, Competence, Work Effectiveness

\section{A. PENDAHULUAN}

Salah satu faktor penentu baiknya kinerja suatu oganisasi adalah memiliki sumber daya manusia yang memiliki keahlian, pengetahuan, dan kemampuan. Unsur-unsur yang dimiliki oleh sumber daya manusia tersebut tentunya berpotensi terhadap pencapaian tujuan dalam suatu organisasi. Adapun kemajuan zaman yang diiringi percepatan pertumbuhan teknologi, arus informasi yang cepat tanpa batas, dan tersedianya fasilitas yang memadai, namun tidak memiliki sumber daya manusia yang kompeten dibidangnya dan didukung dengan adanya sistem pengawasan yang 
konsisten maka menjadi kerja yang berat bagi manajemen organisasi untuk mencapai targetnya.

Pengawasan merupakan suatu cara dalam berorganisasi untuk meningkatkan kinerja yang tepat, sesuai target dan efisien, serta dapat mendukung untuk terwujudnya visi dan misi manajemen organisasi (Fahmi, 2016). Pengawasan dalam organisasi dapat dikatakan menjadi salah satu prioritas yang harus dilakukan mengingat target yang ingin dicapai oleh manajemen organisasi akan dapat tercapai atau tidak tergantung dari bagaimana setiap sumber daya manusia yang terkait dalam membuat perencanaan, melakukan tindak lanjut dari rencana dan melakukan evaluasi atas jalannya organisasi yang bersangkutan. Namun disisi lain tidak semua manusia memiliki keahlian, pengetahuan dan kemampuan bahkan mempunyai keterbatasan dalam memahami dan menjabarkan pekerjaannya yang akhirnya menimbulkan berbagai konsekuensi seperti kesalahan-kesalahan penjabaran pekerjaan. Untuk itu perlu diantisipasi terjadinya kesalahan-kesalahan tersebut dengan melakukan pengawasan kerja baik pengawasan langsung maupun pengawasan tidak langsung.

Kompetensi merupakan suatu kemampuan seseorang untuk menghasilkan sesuatu pada tingkat yang memuaskan ditempat kerja, termasuk kemampuan seseorang untuk membagi dan menerapkan kemampuan, keterampilan, dan pengetahuan yang ada pada dirinya diberbagai kondisi dalam suatu organisasi (Wibowo, 2016). Dengan demikian kompetensi sumber daya manusia dapat dikatakan sebagai faktor penentu dalam pencapaian tujuan, maka sumber daya manusia dalam suatu organisasi harus memiliki kompetensi serta kemampuan untuk dapat menyelesaikan pekerjaan yang telah ditetapkan kepadanya.

Pengawasan dan kompetensi merupakan sistem yang saling berhubungan dalam suatu organisasi yang mampu menunjang pencapaian suatu tujuan karena dengan pengawasan dapat meningkatkan disiplin kerja dan semangat dalam bekerja sedangkan kompetensi yang dimiliki memungkinkan berbagai masalah-masalah yang terjadi dapat dipecahkan dan dapat mengurangi hal-hal yang tidak diinginkan seperti pemborosan waktu, tenaga, dan lain-lain. Pada dasarnya apabila pengawasan dan kompetensi diterapkan sebagaimana mestinya maka akan mampu meningkatkan efektivitas kerja.

Efektivitas kerja merupakan kemampuan dalam memilih tujuan yang tepat serta peralatan yang tepat untuk mencapai tujuan yang telah ditetapkan (Handoko, 2011). Efektivitas juga dapat dikatakan sebagai penyelesaian pekerjaan dengan tepat waktu disertai dengan mutu dan kuantitas yang dihasilkan dan sesuai dengan target yang telah ditetapkan. Pelaksanaan suatu pekerjaan dinilai memenuhi ukuran tertentu yang tidak dapat diganggu gugat bila mengacu pada hasil pekerjaan yang telah ditetapkan dan dicapai secara maksimal.

Untuk mencapai tujuannya organisasi tidak terlepas dari pemanfaatan sumber daya manusia dalam melaksanakan pekerjaannya. Sebagai salah satu organisasi yang memiliki tujuan dalam pelaksanaannya, maka akan tercapai jika didukung oleh semua unsur-unsur yang ada dalam organisasi. Tidak hanya dukungan unsur finansial tetapi juga unsur manusia serta sistem yang ada didalamnya seperti sistem pengawasan, dan sumber daya manusia yang memiliki kemampuan dibidangnya. 


\section{B. KAJIAN TEORI}

\section{Pengawasan}

(Fahmi, 2016) mendeskripsikan pengawasan adalah evaluasi terhadap suatu organisasi atau kegiatan dengan tujuan untuk memenuhi tugasnya dengan baik dan mencapai tujuan yang telah ditetapkan. (Siagian, 2012) mendeskripsikan pengawasan merupakan upaya yang dilakukan untuk menjamin kinerja pegawai sesuai dengan rencana yang telah ditetapkan melalui pemilihan cara-cara observasi penjabaran pelaksanaan kerja yang tepat. Teknik pengawasan menurut (Noor, 2013) menjelaskan proses pengawasan pada dasarnya dilaksanakan dengan menggunakan dua macam teknik yaitu:

a. Pengawasan Langsung (Direct Contro/), yaitu apabila pimpinan organisasi mengadakan sendiri pengawasan terhadap kegiatan yang sedang dijalankan

b. Pengawasan Tidak Langsung (Indirect Control), yaitu pengawasan dari jarak jauh dan pengawasan ini dilakukan melalui laporan yang disampaikan oleh para bawahan laporan itu dapat berbentuk tulisan maupun lisan.

Dari pendapat ahli diatas dapat disimpulkan pengawasan adalah suatu proses penilaian melalui pengamatan, pelaksanaan berbagai kegiatan organisasi guna mencapai tujuan organisasi.

\section{Kompetensi}

(Wibowo, 2016) mendefinisikan kompetensi merupakan kemampuan menjalankan tugas atau pekerjaan yang dilandasi oleh pengetahuan, keterampilan, dan didukung oleh sikap yang menjadi karakteristik individu dalam suatu organisasi. (Torang, 2016) menjelaskan kompetensi merupakan suatu kemampuan untuk melaksanakan atau melakukan aktivitas atau pekerjaan atau tugas. Kompetensi juga merupakan ciri-ciri individu yang mendasari kinerja atau prilaku didalam organisasi.

Faktor-faktor yang mempengaruhi kompetensi menurut (Wibowo, 2016) menggolongkan bahwa terdapat beberapa faktor yang dapat mempengaruhi kecakapan kompetensi seseorang yaitu keyakinan dan nilai-nilai, keterampilan, pengalaman, karakteristik keperibadian, motivasi, isu emosional dan kemampuan intelektual.

Tipe Kompetensi (Torang, 2016) menjelaskan bahwa ada beberapa tipe kompetensi yaitu :

a) Planning Competency merupakan kemampuan menyusun rencana menetapkan visi, misi dan strategi

b) Influence Competency merupakan kemampuan mempengaruhi orang lain untuk melakukan sesuatu atau bekerja.

c) Communication Competency merupakan kemampuan berbicara, mendengarkan orang lain, komunikasi tertulis dan nonverbal.

d) Self Management Competency merupakan kemampuan memotivasi diri, bertindak dengan percaya diri, mengelolah pembelajaran sendiri, fleksibilitas dan berinisiatif.

Dari pendapat ahli diatas dapat disimpulkan kompetensi adalah kemampuan berupa nilai-nilai, pengetahuan, keterampilan, pengalaman dan kepribadian yang dimiliki oleh seseorang untuk menjalankan aktivitas pekerjaan.

\section{Efektivitas Kerja}

(Ridhotullah \& Jauhar, 2015) mendefinisikan efektivitas kerja yaitu proses kerja perusahaan yang tepat dalam mencapai sasaran-sasaran (target) yang telah 
ditetapkan manajemen perusahaan. (Silalahi, 2015) mendefinisikan bahwa efektivitas adalah kemampuan untuk memilih tujuan atau sasaran yang tepat dalam mencapainya. Karena itu efektivitas menunjuk pada apa yang sudah dicapai, sesuai tujuan yang telah ditetapkan, dan dengan rencana atau hasil yang diharapkan.

Faktor-Faktor yang mempengaruhi efektivitas kerja menurut (Sutrisno, 2019) mengemukakan faktor-faktor yang mempengaruhi efektivitas kerja yaitu :

a) karakteristik organisasi, termasuk teknologi dan struktur

b) karakteristik lingkungan, termasuk lingkungan internal dan lingkungan eksternal.

c) Karakteristik karyawan, meliputi keterikatan pada organisasi dan prestasi kerja

d) Kebijakan praktek manajemen

Dari pendapat ahli diatas dapat disimpulkan efektivitas kerja adalah suatu proses pencapaian tujuan tugas melalui pemilihan rencana dan sasaran yang tepat.

\section{METODE PENELITIAN}

Pada studi ini peneliti menggunakan metode penelitian kuantitatif. (Sugiyono, 2018) mendefinisikan penelitian kuantitatif adalah studi dengan berlandaskan pada filsafat positivisme, studi dilakukan pada populasi atau sampel dengan pertimbangan-pertimbangan tertentu, data dikumpulkan menggunakan instrumen penelitian berupa kuisioner, dan analisis data bersifat kuantitatif, dengan sasaran untuk mendapatkan jawaban atas permasalahan penelitian. Variabel dalam studi ini yaitu variabel independen atau variabel yang menjadi sebab berubahnya nilai variabel dependen. Variabel independen pada studi ini adalah pengawasan dan kompetensi. Variabel dependen adalah variabel yang menjadi akibat, karena adanya variabel independen. Variabel independen pada studi ini adalah efektivitas kerja.

Objek penelitian yang menjadi populasi pada studi ini adalah seluruh pegawai kantor Pengadilan Tata Usaha Negara sebanyak 39 orang. Penentuan sampel dalam penelitian ini menggunakan teknik sampling sensus. (Sugiyono, 2018) mengatakan bahwa teknik sampling sensus adalah cara penentuan sampel berupa semua populasi dijadikan sampel. Dengan demikian jumlah sampel dalam penelitian ini sebanyak 39 responden. Data yang digunakan dalam penelitian ini adalah data primer. Data primer didefinisikan sebagai data yang belum pernah diolah dan langsung dikumpulkan oleh peneliti. Biasanya pengumpulan data menggunakan kuisioner, demikian juga pada studi ini. Kuesioner merupakan seperangkat pertanyaan tertulis yang disampaikan kepada responden untuk dijawab sehingga dapat digunakan untuk analisis selanjutnya. Untuk membantu peneliti dalam mengumpulkan data maka peneliti menggunakan google form. Tanggapan responden bersifat kuantitatif dengan teknik pengukuran skala likert setiap tanggapan terhadap butir kuesioner diberi skor dengan lima pilihan tanggapan yaitu sangat setuju (SS) dengan skor 5 , setuju (S) dengan skor 4 , ragu-ragu (RG) dengan skor 3, tidak setuju (TS) dengan skor 2, dan sangat tidak setuju (STS) dengan skor 1.

\section{HASIL PENELITIAN}

a) Uji Normalitas 
Tabel Uji Normalitas One-Sample Kolmogorov-Smirnov Test

\begin{tabular}{|ll|r|r|r|}
\hline & & Pengawasan & Kompetensi & Efektivitas Keria \\
\hline N & & 39 & 39 & 39 \\
Normal Parametersa.b & Mean & 42.28 & 41.92 & 43.44 \\
& Std. Deviation & 4.989 & 4.379 & 5.190 \\
Most Extreme Differences & Absolute & .164 & .173 & .182 \\
& Positive & .164 & .173 & .182 \\
Kolmogorov-Smimov Z & Negative & -.131 & -.106 & -.153 \\
Asymp. Sig. (2-tailed) & & 1.021 & 1.082 & .136 \\
\hline
\end{tabular}

a. Test distribution is Normal.

b. Calculated from data.

Dari tabel diatas dapat dijelaskan terdapat nilai Sig variabel pengawasan 0.248 , variabel kompetensi 0.192 dan variabel efektivitas kerja 0.151. Nilai-nilai Sig setiap variabel telah melampaui 0.05 sehingga data-data yang dikumpulkan berdistribusi normal.

b) Uji Multikolonieritas

\section{Tabel Uji Multikolinieritas}

Coefficients $^{a}$

\begin{tabular}{|rl|r|r|}
\hline \multicolumn{2}{|l|}{ Model } & \multicolumn{2}{|c|}{ Collinearity Statistics } \\
\cline { 3 - 4 } & & Tolerance & \multicolumn{1}{c|}{ VIF } \\
\hline \multirow{2}{*}{1} & (Constant) & & \\
& Pengawasan & .912 & 1.097 \\
& Kompetensi. & .912 & 1.097 \\
\hline
\end{tabular}

Dari hasil tabel diatas dapat diketahui bahwa nilai VIF variabel pengawasan sebesar 1.097 atau kurang dari 10 dan tolerance value sebesar 0.912 atau lebih besar dari 0.10 , nilai VIF variabel kompetensi sebesar 1.097 atau kurang dari 10 dan tolerance value sebesar 0.912 atau lebih besar dari 0.10 maka dapat disimpulkan tidak terjadi multikolinieritas antar variabel bebas.

c) Uji Heteroskedastisitas

\section{Tabel Hasil Uji Glejser}

Coefficients $^{a}$

\begin{tabular}{|c|c|c|c|c|c|c|}
\hline \multirow{2}{*}{\multicolumn{2}{|c|}{ Model }} & \multicolumn{2}{|c|}{ Unstandardized Coefficients } & \multirow{2}{*}{$\begin{array}{c}\begin{array}{c}\text { Standardized } \\
\text { Coefficients }\end{array} \\
\text { Beta }\end{array}$} & \multirow[t]{2}{*}{$\mathrm{t}$} & \multirow[t]{2}{*}{ Sig. } \\
\hline & & B & Std. Error & & & \\
\hline \multirow{3}{*}{1} & (Constant) & 7.407 & 4.817 & & 1.538 & .133 \\
\hline & Pengawasan & -.119 & .090 & -.226 & -1.329 & .192 \\
\hline & Kompetensi & .020 & .102 & .034 & .198 & .845 \\
\hline
\end{tabular}

a. Dependent Variable: abr_res

Dari hasil analisis table diatas menunjukkan bahwa nilai Sig dari uji Glejser untuk variabel Pengawasan sebesar 0.192 atau lebih besar dari 0.05 dan variabel Kompetensi sebesar 0.845 atau lebih besar dari 0.05 maka dapat disimpulkan tidak terjadi heteroskedastisitas. 
d) Analisis Regresi Linier Berganda

Tabel Hasil Analisis Regresi Linier Berganda Coefficients $^{\mathrm{a}}$

\begin{tabular}{|c|c|c|c|c|c|c|}
\hline \multirow{2}{*}{\multicolumn{2}{|c|}{ Model }} & \multicolumn{2}{|c|}{$\begin{array}{c}\text { Unstandardized } \\
\text { Coefficients }\end{array}$} & \multirow{2}{*}{$\begin{array}{c}\text { Standardized } \\
\text { Coefficients } \\
\text { Beta } \\
\end{array}$} & \multirow[t]{2}{*}{$\mathrm{t}$} & \multirow[t]{2}{*}{ Sig. } \\
\hline & & $\mathrm{B}$ & Std. Error & & & \\
\hline \multirow{3}{*}{1} & (Constant) & 9.742 & 7.874 & & 1.237 & .224 \\
\hline & Pengawasan & .447 & .146 & .430 & 3.055 & .004 \\
\hline & Kompetensi & .352 & .167 & .297 & 2.112 & .042 \\
\hline
\end{tabular}

a. Dependent Variable: Efektivitas Keria

Berdasarkan hasil uji regresi linier berganda, maka diperoleh nilai konstanta (a) sebesar 9.742 dan nilai koefisien regresi (b1) sebesar 0.447 dan nilai (b2) sebesar 0,352 dengan demikian diperoleh persamaan regresi sebagai berikut:

$\mathrm{Y}=9.742+0.447 \mathrm{X} 1+0.352 \mathrm{X} 2$

Analisis Koefisien Determinasi

Tabel Hasil Analisis Koefisien Determinasi

Model Summary

\begin{tabular}{|l|r|r|r|r|}
\hline Model & \multicolumn{1}{|c|}{ R } & R Square & \multicolumn{1}{|c|}{$\begin{array}{c}\text { Adjusted R } \\
\text { Square }\end{array}$} & $\begin{array}{c}\text { Std. Error of the } \\
\text { Estimate }\end{array}$ \\
\hline 1 & $.591^{\mathrm{a}}$ & .349 & 313 & 4.301 \\
\hline
\end{tabular}

a. Predictors: (Constant), Kompetensi, Pengawasan

Berdasarkan tabel di atas diperoleh nilai $R$ square sebesar atau 0,349 atau koefisien determinasinya sebesar $34,9 \%$. Artinya kontribusi variabel pengawasan dan variabel kompetensi terhadap variabel efektivitas kerja 34,9\% sedangkan sisanya $65,1 \%$ disumbangkan oleh faktor-faktor lain yang tidak diteliti.

e) Analisis Uji t (Secara Parsial)

\section{Tabel Hasil Analisis Uji t}

Coefficients $^{\mathrm{a}}$

\begin{tabular}{|c|c|c|c|c|c|c|}
\hline \multirow{2}{*}{\multicolumn{2}{|c|}{ Model }} & \multicolumn{2}{|c|}{$\begin{array}{c}\text { Unstandardized } \\
\text { Coefficients }\end{array}$} & \multirow{2}{*}{$\begin{array}{c}\text { Standardized } \\
\text { Coefficients } \\
\text { Beta } \\
\end{array}$} & \multirow[t]{2}{*}{$\mathrm{t}$} & \multirow[t]{2}{*}{ Sig. } \\
\hline & & $\mathrm{B}$ & Std. Error & & & \\
\hline \multirow{3}{*}{1} & (Constant) & 9.742 & 7.874 & & 1.237 & .224 \\
\hline & Pengawasan & .447 & .146 & .430 & 3.055 & .004 \\
\hline & Kompetensi & .352 & .167 & .297 & 2.112 & .042 \\
\hline
\end{tabular}

a. Dependent Variable: Efektivitas Kerja

Berdasarkan hasil uji $\mathrm{t}$ dengan variabel bebas pengawasan diperoleh nilai probabilitas Sig sebesar 0.004 atau lebih kecil dari 0,05 maka Ho ditolak dan Ha diterima. Berdasarkan uji $\mathrm{t}$ dengan variabel bebas kompetensi diperoleh nilai probabilitas Sig sebesar 0,042 atau lebih kecil dari 0,05 maka Ho ditolak dan $\mathrm{Ha}$ diterima. 
f) Analisis Uji F (Secara Simultan)

ANOVAa

Tabel Hasil Analisis Uji F

\begin{tabular}{|rl|r|r|r|r|r|}
\hline Model & & Sum of Squares & df & Mean Square & F & Sig. \\
\hline \multirow{4}{*}{1} & Regression & 357.733 & 2 & 178.866 & 9.671 & $.000^{\mathrm{b}}$ \\
& Residual & 665.857 & 36 & 18.496 & & \\
& Total & 1023.590 & 38 & & & \\
\hline
\end{tabular}

a. Dependent Variable: Efektivitas Kerja

b. Predictors: (Constant), Kompetensi, Pengawasan

Berdasarkan hasil uji $\mathrm{F}$ diperoleh nilai probabilitas Sig sebesar 0,000 atau lebih kecil dari 0,05 maka Ho ditolak dan Ha diterima.

\section{E. PEMBAHASAN}

1. Pengaruh Pengawasan Terhadap Efektivitas Kerja Pegawai

Uji hipotesis $(\mathrm{H} 1)$ dengan uji t terhadap variabel pengawasan dan variabel terikat efektivitas kerja menghasilkan nilai probabilitas sig 0,004 atau lebih kecil dari 0,05 maka Ho1 ditolak dan Ha1 diterima. Penerimaan Ha1 berarti secara parsial pengawasan berpengaruh signifikan terhadap efektivitas kerja pegawai. Hasil penelitian ini konsisten dengan hasil penelitian yang telah dilakukan oleh (Rinaldi, Goh, \& Julitawaty, 2018) yang menyatakan bahwa pengawasan secara parsial berpengaruh signifikan terhadap efektivitas kerja. Hal ini berkaitan dengan pendapat (Siagian, 2012) mendefinisikan pengawasan merupakan keseluruhan upaya pengamatan pelaksanaan kegiatan operasional guna menjamin bahwa berbagai kegiatan tersebut sesuai dengan rencana yang telah ditetapkan sebelumnya.

\section{Pengaruh Kompetensi Terhadap Efektivitas Kerja Pegawai}

Uji hipotesis $(\mathrm{H} 2)$ dengan uji t terhadap variabel kompetensi dan variabel terikat efektivitas kerja menghasilkan nilai probabilitas Sig sebesar 0,042 atau lebih kecil dari 0,005 maka $\mathrm{Ho} 2$ ditolak dan $\mathrm{Ha} 2$ diterima. Penerimaan $\mathrm{Ha} 2$ berarti secara parsial, kompetensi berpengaruh signifikan terhadap efektivitas kerja pegawai.

Hasil penelitian ini konsisten dengan hasil penelitian yang telah dilakukan oleh (Zaini \& Agustian, 2019) yang menyatakan bahwa secara parsial kompetensi pengaruh signifikan terhadap efektivitas kerja pegawai. Hal ini berkaitan dengan pendapat (Wibowo, 2016) mendefinisikan kompetensi merupakan kumpulan keahlian, kemampuan melaksanakan tugas atau pekerjaan yang dilandasi oleh pengetahuan, keterampilan, dan didukung oleh sikap yang menjadi karakteristik individu dalam suatu organisasi.

\section{Pengaruh Pengawasan dan Kompetensi terhadap efektivitas kerja pegawai}

Uji hipotesis $(\mathrm{H} 3)$ dengan uji $F$ terhadap variabel bebas pengawasan dan kompetensi dengan variabel terikat efektivitas kerja menghasilkan nilai probabilitas Sig 0,000 atau $\leq$ 0,05 maka Ho3 ditolak dan Ha3 diterima. Penerimaan Ha3 menunjukkan bahwa secara bersama-sama pengawasan dan kompetensi mampu menaikkan secara signifikan terhadap efektivitas kerja pegawai.

Hal ini sejalan dengan pendapat (Handoko, 2011) mendeskripsikan efektivitas kerja merupakan kemampuan dalam menentukan cara dan alat yang tepat untuk memenuhi target organisasi yang telah ditetapkan. Hasil penelitian ini juga konsisten 
dengan hasil penelitian terdahulu oleh (Akbar, Sasmita, \& Hamid, 2014) yang menyatakan secara bersama-sama pengawasan dan kompetensi berpengaruh signifikan terhadap efektivitas kerja pegawai.

\section{F. KESIMPULAN DAN SARAN}

Dari kajian yang dilakukan terhadap jawaban responden penelitian maka dapat disimpulkan beberapa hal yaitu: pengawasan dapat meningkatkan efektivitas kerja pegawai, kompetensi mampu menaikkan efektivitas kerja pegawai, dan secara bersama-sama pengawasan dan kompetensi bisa memberikan peningkatan signifikan efektivitas kerja pegawai. Untuk itu organisasi sebaiknya melakukan upaya-upaya meningkatkan efektivitas kerja pegawai melalui pengawasan secara lansung di lingkungan kerja, sehingga dapat dilakukan pemantauan langsung kepada pegawai dengan harapan bisa mengevaluasi dan memperbaiki efektivitas kerja pegawai dalam melakukan suatu pekerjaan. Selain itu oragnisasi juga sebaiknya memberikan program pelatihan dan pengembangan karir agar pegawai dapat meningkatkan kompetensinya dan memiliki rasa tanggung jawab didalam melaksanakan pekerjaannya. Untuk kajian masa depan, diperlukan untuk memperluas studi dengan faktor-faktor lain sebagai penentu efektivitas kerja.

\section{DAFTAR PUSTAKA}

Akbar, R., Sasmita, J., \& Hamid, L. (2014). Pengaruh Pengawasan dan Kompetensi terhadap Kinerja Karyawan pada Hotel Permai Pekanbaru. JOM Fekon, Vol.1(No.2), 1-15.

Fahmi, I. (2016). Pengantar manajemen sumber daya manusia : konsep dan kinerja. Jakarta: Mitra Wacana Media.

Handoko, T. H. (2011). Manajemen. Yogyakarta: BPFE.

Noor, J. (2013). Penelitian IImu Manajemen. Jakarta: Kencana Prenada Media Group.

Ridhotullah, S., \& Jauhar, M. (2015). Pengantar Manajemen. Jakarta: Prestasi Pustaka Raya.

Rinaldi, Goh, T. S., \& Julitawaty, W. (2018). Pengaruh Pengawasan dan Semangat Kerja terhadap Efektivitas Kerja Karyawan PT. Multi Artha Universindo Medan. Jurnal Bisnis Kolega, Vol.4(No.2), 78-84.

Siagian, S. P. (2012). Manajemen Stratejik. Jakarta: PT. Bumi Aksara.

Silalahi, U. (2015). Asas-asas Manajemen. Bandung: PT. Refika Aditama.

Sugiyono. (2018). Metode Penelitian Manajemen,. Bandung: Alfabeta.

Sutrisno, E. (2019). Manajemen Sumber Daya Manusia. Jakarta: Prenada Media Group.

Torang, S. (2016). Organisasi \& Manajemen. Bandung: Alfabeta. 
Wibowo. (2016). Manajemen Kinerja. Jakarta: PT. Raja Grafindo Persada.

Zaini, Z., \& Agustian, R. (2019). Pengaruh Kompetensi Pegawai dan Disiplin Kerja terhadap Efektivitas Kerja Pegawai pada Kantor Imigrasi Kelas I Jakarta Utara. Jurnal Transparansi, Vol.2(No.1), 109-115. 